\title{
Study on Drug electronic Supervision Based on Flows Monitoring
}

\author{
Bo Jiang and Zikui Lin \\ School of Economics and Management, Beijing Jiaotong University, \\ Beijing, China \\ zklin@bjtu.edu.cn
}

\begin{abstract}
Drugs are special goods for preventing, treating and diagnosing disease in order to assure people's health. The quality of drugs is directly related to people's kedlth. Drug electronic supervision is a kind of technology model to strigngthen the drug circulation regulation, being of great significance to guarantee drug safety. Bdsed on the flows monitoring of drug logistics system, we combine qualitative analyser and quantitative researches, theory researches and simulation analyses togethen A network flows real-time monitoring model is established in this paper and the simulation results show that the model can automatically monitor the drug cireulation of the entire system in real-time.
\end{abstract}

Keywords: Drug; Circulation; Logistics, Regulatien; Flows

\section{Introduction}

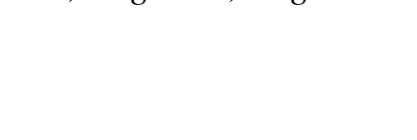

As a kind of special commodity, drugs production and circulation must be under government regulation[1]. Alt present Chinese drug circulation regulation system is increasingly perfect and the technology of drug supervision is gradually innovated and remarkable achievements have been made in the aspects of strengthening drug supervision administration and standardizing the order of drug circulation[2]. The existing electronic supervision which uses the mode of monitoring code is fully traceable in the way of 'one thing one code $[3]$. This electronic supervision mode with high precision and good anti-counterfeiting performance can response to emergencies timely, ensuring effective regulation of drug girculation. However, this high-cost supervision pattern whose technical requirements stay ata relative high level is extremely dependent on information network and has a high network load; making the comprehensive promotion of this supervision pattern is difficult[4]. Consequently, a new drug circulation electronic monitoring method should be found.

Electronic monitoring and drug logistics have been intensively studied in the research literature. In regard of electronic monitoring, Crowe (2002) introduced the flexibility of electronic supervision and provided information on electronic supervision technologies used in correctional institutions[5]. De Michele and Payne (2010) discussed the baseline information on evidence-based practices to provide a better understanding of what electronic supervision could realistically work[6]. DING Jin-xi (2011) presented an in-depth analysis including the purpose, features and implementing steps toward drug electronic supervision policy, and then pointed out that Drug electronic supervision is a natural trend but still in its infancy[7]. Ma Xiaoyu(2014) suggested that there were many problems with the electronic monitoring system of medicines in China. It was proposed that the legal status and law enforcement of electronic monitoring be strengthened; monitoring technology be improved; publicity be enhanced to raise consumer awareness and encourage public supervision, in order to establish the coexistence of electronic monitoring system and the essential drug system[8]. Bi Wenyan(2014) discussed that for 
pharmaceutical enterprises, the key approaches to smooth implementation of the electronic supervision project for drugs of all varieties should include, a comprehensive consideration of cost with actual conditions, a scientific plan based on long terms and enhancement of risk management of the electronic code[9] . In regard of drug logistics, Hong Gang (2009)studied on the development progress of drug logistics in China, including the drug logistics development background, administration system, distribution mode and development. Feature in various economic phase[10].Guo Shaolai(2008) optimized the procedure of drug purchase and established a drug supply logistics system to improve the ability of drug supply logistics and the level of material management[11]. He Xuejun(2012) summed up the six tendencies concerning the development of the pharmaceutical industry by analyzing the present pharmaceutical supply chain model. These tendencies include revealing the advantages of chain drug stores, increasing the pharmaceutical logistics centers, the application of $\mathrm{E}$-commerce in pharmaceutical industry, the foreign investment in pharmaceutical enterprises, the standardization and informatization of pharmaceutical logistics and the trend of $>$ third-party pharmaceutical logistics[12]. Xia Xudong(2009) suggested that through stablishing the concept of outsourcing, constructing the information platform and improving the relevant policies and regulations to facilitate the development of medical 3PL[13].

Based on the previous studies, this paper discusses a new drug circulation electronic monitoring method which can find the circulation abnormalities in real-time through the flows monitoring of drug logistics system. The results of research provide the basis for further investigation of abnormal points and correspending disposal, so as to achieve the purpose of drug circulation regulation

\section{Network Flows Regulation Mechânism of Drug Logistics System}

The drugs that have the same approval number and batch number in Chinese drug circulation can only be produced by one pharmaceutical manufacturer, and can be uniquely identified in its life cycle[14]. Wephut the drug logistics system as the research object. The wholesalers and retallers, which are the nodes in the logistics system $[15,16]$, constitute a 'being monitored system', which are as shown in Figure 1.

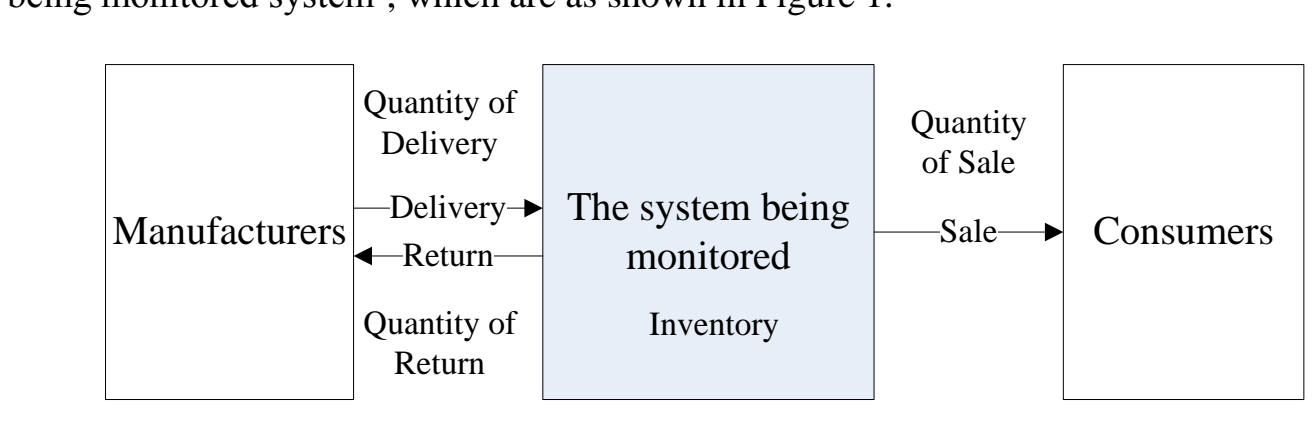

\section{Figure 1. Mechanism of the Flows Monitoring}

For a batch of drugs that has unique identification code, we can infer whether the drug logistics system is mixed in illegal drugs by judging the cumulative input flow whether is equal to the sum of cumulative output flow with the current system inventory. For the convenience of calculation, we introduce an indicator, which is the coefficient of Drug Logistics System Network Total Flow Monitoring. This indicator can be calculated by the difference between cumulative inputs flow and the sum of cumulative outputs flow with the current system inventory.

Specifically speaking, the initial inventory of each subject in the system being monitored is 0 before the drugs flowing into. In the monitoring process, the system will automatically calculate the Drug Logistics System Network Total Flow Monitoring Coefficient and the 
current inventories of all subjects in the system, and compare the calculated results with 0 .

(1) When the value of coefficient is equal to 0 , there are two situations:

1) If the current inventory value of each subject is non-negative, we can conclude that the system being monitored is not mixed in illegal drugs and the drug circulation situation is normal.

2)If there is a subject whose current inventory value is negative in the system being monitored, it means that the subject once has made illegal drugs and sold outside, or there is the phenomenon of not reporting flow information. Drug circulation situation is abnormal at this time point.

(2) When the value of coefficient is less than 0 , we can conclude that the system being monitored is mixed with illegal drugs and the drug circulation situation is abnormal.

3hf the value of coefficient is more than 0 , it means some drugs which are produced by manufacturers do not flow into the monitoring system or there is a network node who sells drugs to consumers outside the system. Although the two cases are irregularities, drugs in the circulation are legal. We can conclude that there are no illegal drigs in the drug circulation.

\section{The Model of Monitoring and Management of Drug Logistics System Network Flows}

\subsection{Model Assumptions and Symbols Definitions}

The assumption running environment of the Drug Rogistics System is as follows:

(1)Due to the multi-level wholes Aer system has the same monitoring mechanisms as one-level's, the Drug Logistics System selects a simplified 'divergent - symmetry type' network structure [17], as shown in Figure 2.

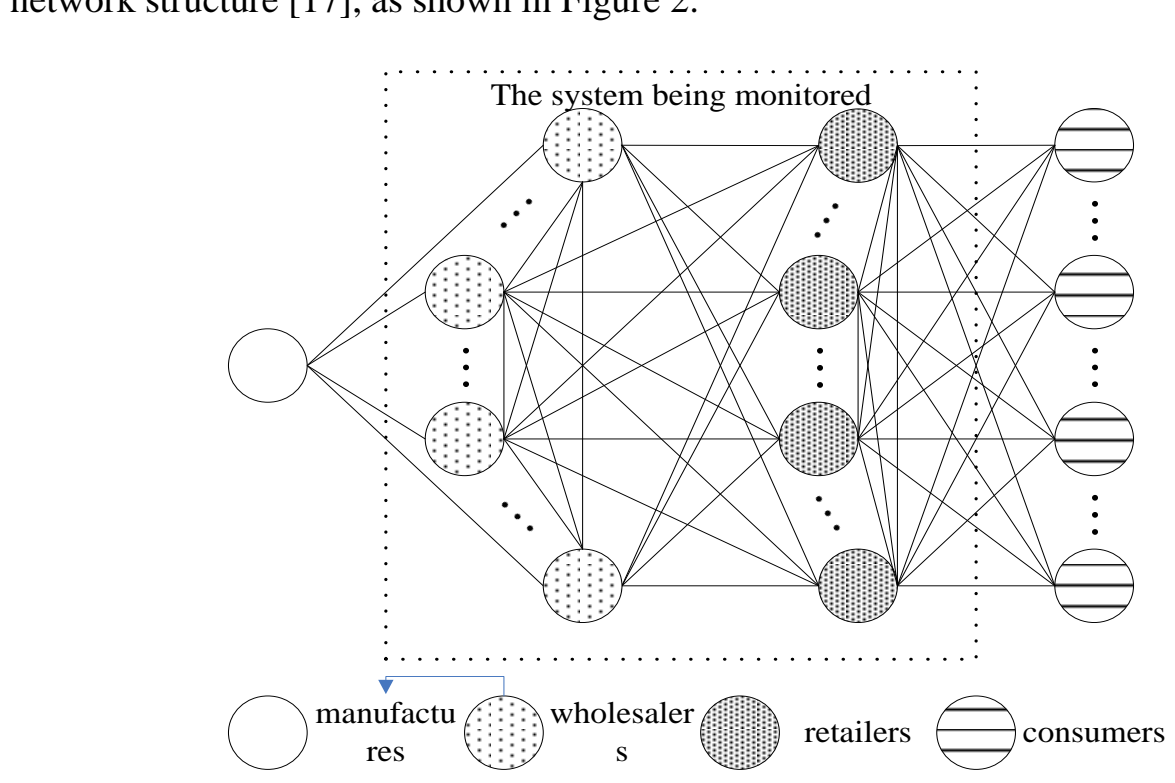

\section{Figure 2 Network Structure of the Drug Logistics System for the Flows Monitoring Model}

(2)The circulating medicine in the monitoring system is a batch of new drugs which have the same approval number and batch number. The initial inventory of each node is zero. (3)Drug transportation activities between each node are instantaneously completed. In the establishment of the Real-time Flows Monitoring Network Traffic Model of drug logistics system, the involved symbols' definitions ${ }^{[18]}$ are as shown in Table 1. 
Table1Symbol Definition of the Flows Monitoring Model

\begin{tabular}{|c|c|}
\hline Symbol & Definition \\
\hline$t$ & $\begin{array}{l}\text { State parameters of the system, recording each discrete point in time, whose initial } \\
\text { value is zero. As long as there is any node uploading traffic information, the time } \\
\text { state of system is updated from } t \text { to } t+1 \text { point. }\end{array}$ \\
\hline$n$ & The number of wholesalers in the system \\
\hline$m$ & The number of retailers in the system \\
\hline$\lambda_{i t}^{f}$ & $\begin{array}{l}\text { The determination coefficient of whether manufacturers have carried drugs to the } \\
\text { ith wholesaler during t to } t+1 \text { point. } 0-1 \text { variable. }\end{array}$ \\
\hline$f_{i t}$ & $\begin{array}{l}\text { The quantity of drugs delivering from manufacturers to the } i t h \text { wholesaler during } t \\
\text { to } t+1 \text { point. }\end{array}$ \\
\hline$\lambda_{i t}^{\bar{f}}$ & $\begin{array}{l}\text { The coefficient determination of whether the goods have been arrived which are } \\
\text { ordered by the } \mathrm{i} \text { th wholesaler during } \mathrm{t} \text { to } \mathrm{t}+1 \text { point. } 0-1 \text { variable. }\end{array}$ \\
\hline $\bar{f}_{i t}$ & $\begin{array}{l}\text { The quantity of arrival goods which are received by the ith tholesaler during } t \text { to } \\
\mathrm{t}+1 \text { point. }\end{array}$ \\
\hline$\lambda_{i t}^{g}$ & $\begin{array}{l}\text { The determination coefficient of whether the wholesaley bas returned drugs to } \\
\text { the manufactures during t to } t+1 \text { point. } 0-1 \text { variable. }\end{array}$ \\
\hline$g_{i t}$ & $\begin{array}{l}\text { The quantity of drugs which are returned from the } i t h \text { wholesaler to manufactures } \\
\text { during } t \text { to } t+1 \text { point. }\end{array}$ \\
\hline$\lambda_{i t}^{\bar{g}}$ & $\begin{array}{l}\text { The determination coefficient of whether manufactures have received returned } \\
\text { drugs from the } \mathrm{i} t h \text { wholesalep duing } \mathrm{t} \text { to } t+\text { point. } 0-1 \text { variable. }\end{array}$ \\
\hline $\bar{g}_{i t}$ & $\begin{array}{l}\text { The quantity of drugs manufaetures having received which are returned from the } \\
\text { ith wholesaler during t to } t+1 \text { time point. }\end{array}$ \\
\hline$\lambda_{i h t}^{p}$ & $\begin{array}{l}\text { The determination coefficient of whether the } \mathrm{i} \text { th wholesaler has sent drugs to the } \\
\mathrm{h} t \mathrm{t} \text { retailer during } t \text { to } t+1 \text { point- } 0-1 \text { variable. }\end{array}$ \\
\hline$p_{i h t}$ & $\begin{array}{l}\text { The quantity of arugs whichare delivered from the } \mathrm{i} t h \text { wholesaler to the } \mathrm{h} \text { th retailer } \\
\text { during t to }+1 \text { point. }\end{array}$ \\
\hline$\lambda_{i h t}^{\bar{p}}$ & $\begin{array}{l}\text { The determination coefficient of whether the } \mathrm{h} t h \text { retailer has received drugs which } \\
\text { are sent by the } \mathrm{i} \text { th wholesaler during } \mathrm{t} \text { to } \mathrm{t}+1 \text { point. } 0-1 \text { variable. }\end{array}$ \\
\hline $\bar{p}_{i h t}$ & $\begin{array}{l}\text { The quantity of the } \text { th retailer having received drugs which are ordered by the ith } \\
\text { wholesaler durng to } t+1 \text { point. }\end{array}$ \\
\hline$\lambda_{\text {hit }}^{q}$ & $\begin{array}{l}\text { The determination coefficient of whether the } \mathrm{h} t h \text { retailer has returned drugs to the } \\
\text { ith wholesaler during t to } t+1 \text { point. } 0-1 \text { variable. }\end{array}$ \\
\hline$q_{h i t}$ & $\begin{array}{l}\text { The quantity of drugs returned from the } \mathrm{h} t h \text { retailer to the } \mathrm{i} t h \text { wholesaler during } \mathrm{t} \text { to } \\
\mathrm{t}+1 \text { point. }\end{array}$ \\
\hline & $\begin{array}{l}\text { The determination coefficient of whether the } \mathrm{i} t h \text { wholesaler has received the drugs } \\
\text { that are returned by the } \mathrm{h} t h \text { retailer during } \mathrm{t} \text { to } \mathrm{t}+1 \text { point. } 0-1 \text { variable. }\end{array}$ \\
\hline & $\begin{array}{l}\text { The quantity of the } i t h \text { wholesaler having received drugs which are returned by the } \\
\mathrm{h} t h \text { retailer during } \mathrm{t} \text { to } \mathrm{t}+1 \text { point. }\end{array}$ \\
\hline$\lambda_{i j t}^{w}$ & $\begin{array}{l}\text { The determination coefficient of whether the } \mathrm{i} t h \text { wholesaler has allotted drugs to } \\
\text { the } \mathrm{j} \text { th wholesaler during } \mathrm{t} \text { to } \mathrm{t}+1 \text { point }(i \neq j) .0-1 \text { variable. }\end{array}$ \\
\hline$w_{i j t}$ & $\begin{array}{l}\text { The quantity of drugs which are allotted from the } \mathrm{i} \text { th wholesaler to the } \mathrm{j} \text { th } \\
\text { wholesaler during to } \mathrm{t}+1 \text { point }(i \neq j) \text {. }\end{array}$ \\
\hline$\lambda_{i j t}^{\bar{w}}$ & $\begin{array}{l}\text { The determination coefficient of whether the } \mathrm{j} t h \text { wholesaler has received the drugs } \\
\text { allotted from the } \mathrm{i} t h \text { wholesaler during } \mathrm{t} \text { to } \mathrm{t}+1 \text { point }(i \neq j) .0-1 \text { variable. }\end{array}$ \\
\hline $\bar{w}_{i j t}$ & $\begin{array}{l}\text { The quantity of the } \mathrm{j} t h \text { wholesaler having received drugs which are allotted from } \\
\text { the ith wholesaler during t to } t+1 \text { point }(i \neq j) \text {. }\end{array}$ \\
\hline$\lambda_{h k t}^{r}$ & $\begin{array}{l}\text { The determination coefficient of whether the } \mathrm{h} t h \text { retailer has allotted drugs to the } \\
\mathrm{k} t h \text { wholesaler during t to } \mathrm{t}+1 \text { point }(h \neq k) .0-1 \text { variable. }\end{array}$ \\
\hline
\end{tabular}




\begin{tabular}{|c|c|}
\hline Symbol & Definition \\
\hline$r_{h k t}$ & $\begin{array}{l}\text { The quantity of the } \mathrm{h} t h \text { retailer having allotted drugs to the } \mathrm{k} t h \text { retailer during } \mathrm{t} \text { to } \\
\mathrm{t}+1 \text { point }(h \neq k) \text {. }\end{array}$ \\
\hline$\lambda_{h k t}^{\bar{r}}$ & $\begin{array}{l}\text { The determination coefficient of whether the } \mathrm{k} t h \text { retailer has received drugs which } \\
\text { are allotted from the } \mathrm{h} t h \text { retailer during } \mathrm{t} \text { to } \mathrm{t}+1 \text { point }(h \neq k) .0-1 \text { variable. }\end{array}$ \\
\hline $\bar{r}_{h k t}$ & $\begin{array}{l}\text { The quantity of the } \mathrm{k} t h \text { retailer having received drugs which are allotted from the } \\
\mathrm{h} t h \text { retailer during } \mathrm{t} \text { to } \mathrm{t}+1 \text { point }(h \neq k) \text {. }\end{array}$ \\
\hline$\lambda_{h t}^{s}$ & $\begin{array}{l}\text { The determination coefficient of whether the } \mathrm{h} t h \text { retailer has sold drugs during } \mathrm{t} \text { to } \\
\mathrm{t}+1 \text { point. } 0-1 \text { variable. }\end{array}$ \\
\hline$s_{h t}$ & The quantity of drugs which are sold by the $\mathrm{h} t h$ retailer during $\mathrm{t}$ to $\mathrm{t}+1$ point \\
\hline$f_{i}(t)$ & $\begin{array}{l}\text { Up to } t \text { point, the cumulative amount of drugs which are delivered from the } \\
\text { manufacturers to the } \mathrm{i} t h \text { wholesaler. }\end{array}$ \\
\hline $\bar{f}_{i}(t)$ & $\begin{array}{l}\text { Up to t point, the cumulative amount of } \\
\text { received by the ith wholesaler. }\end{array}$ \\
\hline$g_{i}(t)$ & $\begin{array}{l}\text { Up to t point, the cumulative amount of } \mathrm{d} \\
\text { wholesaler to manufacturers. }\end{array}$ \\
\hline $\bar{g}_{i}(t)$ & $\begin{array}{l}\text { Up to t point, the cumulative amount of manufacturers having received drugs } \\
\text { which are returned from the ith wholesaler. }\end{array}$ \\
\hline$p_{i h}(t)$ & $\begin{array}{l}\text { Up to t point, the cumulative amount of drugs wich are delivered from the ith } \\
\text { wholesaler to the } \mathrm{h} \text { th retailer. }\end{array}$ \\
\hline $\bar{p}_{i h}(t)$ & $\begin{array}{l}\text { Up to t point, the cumulative amount of the } \mathrm{h} \text { th retailer having received drugs } \\
\text { which are ordered from the ith wholesaler. }\end{array}$ \\
\hline$q_{h i}(t)$ & $\begin{array}{l}\text { Up to t point, the cumplative amount of drugs which are returned from the } \mathrm{h} \text { th } \\
\text { retailer to the ith wholesaler. }\end{array}$ \\
\hline $\bar{q}_{h i}(t)$ & $\begin{array}{l}\text { Up to t point, the cumulative amount } \mathrm{of} \text { drugs which are returned by the } \mathrm{h} t h \text { retailer } \\
\text { and received by the ith wholesalet. }\end{array}$ \\
\hline$w_{i j}(t)$ & $\begin{array}{l}\text { Up to t point the cumulative amount of drugs which are allotted from the ith } \\
\text { wholesaler to the } \mathrm{j} \text { th wholesaler }(i \neq j) \text {. }\end{array}$ \\
\hline $\bar{w}_{i j}(t)$ & $\begin{array}{l}\text { Up } 10 \text { point, the cumulative amount of drugs which are received by the } \mathrm{j} \text { th } \\
\text { wholesaler and al oted from the ith wholesaler }(i \neq j) \text {. }\end{array}$ \\
\hline$r_{h k}(t)$ & $\begin{array}{l}\text { Up to t point, the cumulative amount of drugs which are allotted from the } \mathrm{h} t h \\
\text { wholesaler to the } \mathrm{k} t h \text { wholesaler }(h \neq k) \text {. }\end{array}$ \\
\hline $\bar{r}_{h k}(t)$ & $\begin{array}{l}\text { Up to t point, the cumulative amount of drugs which are received by the } \mathrm{k} t h \text { retailer } \\
\text { from the ith retailer allotting }(h \neq k) \text {. }\end{array}$ \\
\hline$s_{h}(t)$ & Up tot point, the cumulative amount of drugs which are sold by the $\mathrm{h} t h$ retailer. \\
\hline & $\begin{array}{l}\text { Up to t point, the total cumulative amount of drugs which outflow from the ith } \\
\text { retailer. }\end{array}$ \\
\hline$w y_{i}(t)$ & $\begin{array}{l}\text { Up to t point, the total cumulative amount of drugs which inflow from the ith } \\
\text { wholesaler. }\end{array}$ \\
\hline$r y_{i}(t)$ & $\begin{array}{l}\text { Up to t point, the total cumulative amount of drugs which inflow from the ith } \\
\text { retailer. }\end{array}$ \\
\hline$w z_{i}(t)$ & At $t$ point time, the drug stock of the ith wholesaler. \\
\hline$r z_{i}(t)$ & At $t$ point time, the drug stock of the ith retailer. \\
\hline$\delta(t)$ & At $t$ point time, the total flow monitoring coefficient of the Drug Logistics System. \\
\hline
\end{tabular}

Due to the 'conservation' of the network flow of the Drug Logistics System, we use symbols to describe each flow of the system. The flow diagram is shown in Figure 3. 


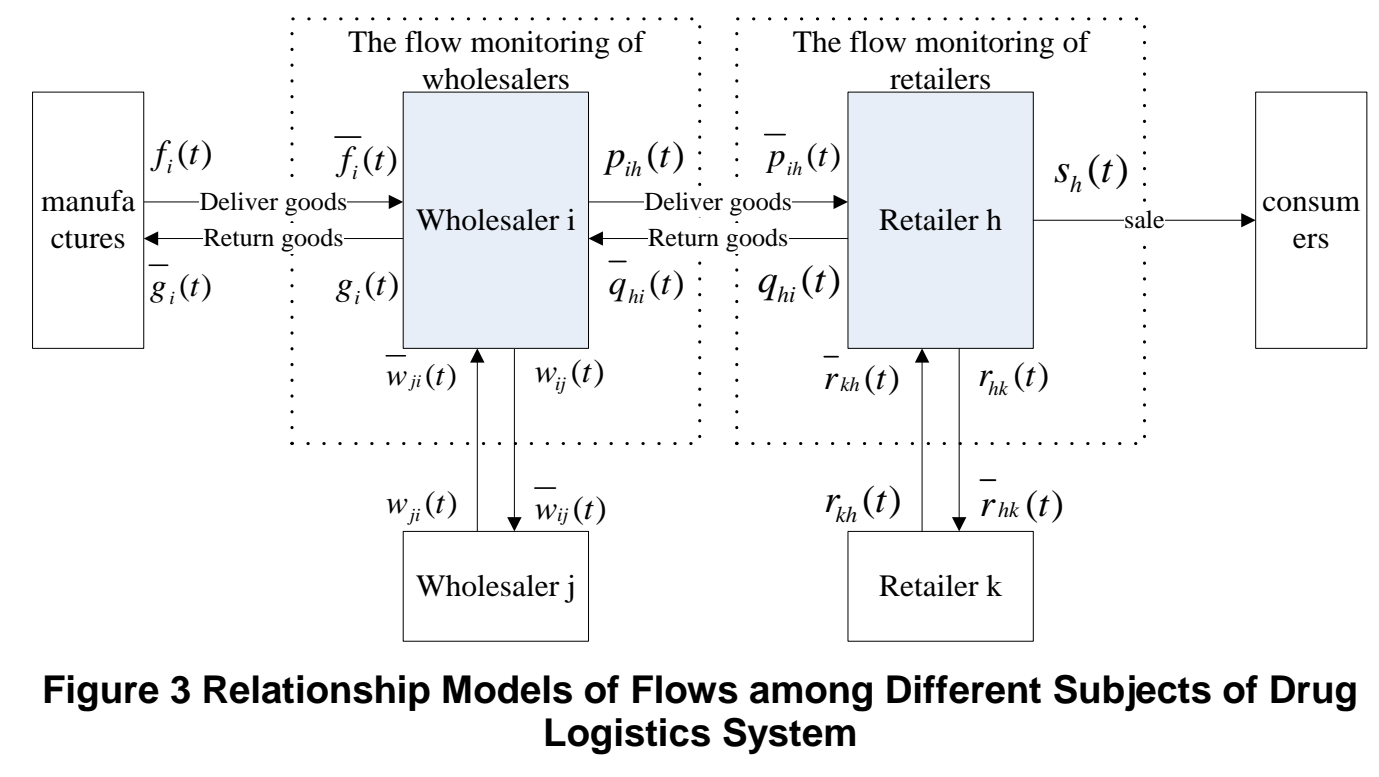

In Figure 3, all kinds of subjects' flows of the brug Logistio System are changing with the state of the system time.

\subsection{The Dynamic Changeable Flow Model}

Because the operation processes of subjects in the system are dynamic, we introduce a system time state parameter ' $t$ 'to reeore each discrete time point of the system, describing the time state of the Drug Logistics System, whose initial value is zero.

As long as any node of the system uploads the information of arrival goods, delivering or selling goods, then time state of the system is updated from $t$ point to $t+1$ point, exactly recording the dynamic processes of the system. During t to $t+1$ time point, the dynamically changeable formulas of yarious subjects' flows in the Drug Logistics System are defined as follow.

(1)Flows between manufacturers and wholesalers

(1) The delivery goods

1) The quantity of the delivery

$$
f_{i}(t+1)=f_{i}(t)+\lambda_{i} \cdot f_{i t} \quad i=1,2, \cdots, n
$$

' $\lambda_{i t}^{f}$ ' is a 0 -1 variable. When' $\lambda_{i t}^{f}=1$ ', it means that the manufacture sends goods to the ith wholesaler, the quantity is ' $\bar{f}_{i t}$ '.

2) The quantity of the arrival

$\bar{f}_{i}(t+1)=\bar{f}_{i}(t)+\lambda_{i t}^{\bar{f}} \cdot \bar{f}_{i t} \quad i=1,2, \cdots, n$

' $\lambda_{i t}^{\bar{f}}$ 'is a $0-1$ variable. When' $\lambda_{i t}^{\bar{f}}=1$ ', it means that the $\mathrm{i}$ th wholesaler receives ' $\bar{f}_{i t}$ ' quantity of goods.

(2)The returned goods

1) The quantity of the delivery

$$
g_{i}(t+1)=g_{i}(t)+\lambda_{i t}^{g} \cdot g_{i t} \quad i=1,2, \cdots, n
$$

' $\lambda_{i t}^{g}$ ' is a $0-1$ variable. When' $\lambda_{i t}^{g}=1$ ', it means that the $\mathrm{i} t h$ wholesaler returns' $g_{i t}$ ' goods to manufacture during $\mathrm{t}$ to $\mathrm{t}+1$ time point.

2) The quantity of the arrival 


$$
\bar{g}_{i}(t+1)=\bar{g}_{i}(t)+\lambda_{i t}^{\bar{g}} \cdot \bar{g}_{i t} \quad i=1,2 ; \cdot n,
$$

' $\lambda_{i t}^{\bar{g}}$ 'is a $0-1$ variable. When ' $\lambda_{i t}^{\bar{g}}=1$ ', it means that manufactures receive goods which are returned by the ith wholesaler.

In the same way, the rest dynamically changeable formulas between subjects are as follows.

\section{(2) Flows between wholesalers and retailers}

(1)The delivery

1) The quantity of the delivery

$p_{i h}(t+1)=p_{i h}(t)+\lambda_{i h t}^{p} \cdot p_{\text {iht }}, i=1,2, \cdots, n, \quad h=1,2, \cdots, m$

2) The quantity of the arrival

$\bar{p}_{i h}(t+1)=\bar{p}_{i h}(t)+\lambda_{i h t}^{\bar{p}} \cdot \bar{p}_{i h t}$

$i=1,2 ; \cdots n, h=1,2, \cdots, m$

(2) The returned goods

1) The quantity of the delivery

$q_{h i}(t+1)=q_{h i}(t)+\lambda_{\text {hit }}^{q} \cdot q_{\text {hit }}$

2) The quantity of the arrival

$\bar{q}_{h i}(t+1)=\bar{q}_{h i}(t)+\lambda_{\text {hit }}^{\bar{q}} \cdot \bar{q}_{h i t}$

$$
h=1,2(\cdots, m i=1,2, \cdots, n
$$

(3)Flows between wholesalers

(1) The quantity of the delivery

$w_{i j}(t+1)=w_{i j}(t)+\lambda_{i j t}^{w} \cdot w_{i j t}$

$i=1,2, \cdots, n j=1,2, \cdots, n$

(2) The quantity of the arrival

$\bar{w}_{i j}(t+1)=\bar{w}_{i j}(t)+\lambda_{i j t}^{\bar{w}} \cdot \bar{w}_{i j t}$

$i=1,2, \cdots, n \quad j=1,2, \cdots, n$

(10)

(4)Flows between retailers

(1)The quantity of the delivery

$r_{h k}(t+1)=r_{h k}(t)+\lambda_{h k t}^{r} \cdot h=1,2, \cdots, m k=1,2, \cdots, m$

(2) The quantity of the arrival

$\bar{r}_{h k}(t+1)=\bar{r}_{h k}(t)+\lambda_{h k t}^{r} \cdot \bar{r}_{h k t} \quad h=1,2 ; \cdot \cdot m k=1,2 ; \cdot \cdots m$

(5)Flows between retailers and consumers

In the Drug Logistics System, one retailer can sell drugs to multiple consumers, thus we use the total number of drugs that all retailers sell to calculate the flow between retailers and constamers.

$s_{h}(t+1)=s_{h}(t)+\lambda_{h t}^{s} \cdot s_{h t}$

$$
h=1,2, \cdots, m
$$

\subsection{The Cumulative Static Flow Model}

Through the establishment of the static cumulative model of the Drug Logistics System Network Flows, we can determine the relationship between different subjects of various flows[19].

(1)Total Outflows of the Nodes in the system

In the Drug Logistics System, the total outflows of the nodes are as shown in Table 2.

Table 2 Total Outflows of the Nodes in the Drug Logistics System 


\begin{tabular}{|c|c|c|c|c|c|c|c|c|c|c|}
\hline & & & & & & \multirow{2}{*}{\multicolumn{3}{|c|}{ retailers }} & \multirow{3}{*}{$\begin{array}{l}\text { man } \\
\text { ufact } \\
\text { ures/ } \\
\text { cons } \\
\text { umer } \\
\text { s }\end{array}$} & \multirow{3}{*}{$\begin{array}{l}\text { Total } \\
\text { outflo } \\
\text { ws of } \\
\text { nodes }\end{array}$} \\
\hline \multirow{2}{*}{\multicolumn{2}{|c|}{$\begin{array}{l}\text { Knflow } \\
\text { nodes } \\
\text { outflo } \\
\text { w } \\
\text { nodes }\end{array}$}} & \multicolumn{4}{|c|}{ wholesalers } & & & & & \\
\hline & & 1 & 2 & $\cdots$ & $n$ & 1 & 2 & $m$ & & \\
\hline w & 1 & 0 & $w_{12}(t)$ & & $w_{1 n}(t)$ & $p_{11}(t)$ & $p_{12}(t)$ & $p_{1 m}(t)$ & $g_{1}(t)$ & $w x_{1}(t)$ \\
\hline $\begin{array}{l}\mathrm{n} \\
\text { ol }\end{array}$ & 2 & $w_{21}(t)$ & 0 & $\cdots$ & $w_{2 n}(t)$ & $p_{21}(t)$ & $p_{22}(t)$ & $p_{2 m}(t)$ & $g_{2}(t)$ & $w x_{2}(t)$ \\
\hline $\begin{array}{l}\text { es } \\
\text { al }\end{array}$ & $\vdots$ & $\vdots$ & $\vdots$ & $\ddots$ & $\vdots$ & & $\vdots$ & & : & $\vdots$ \\
\hline $\begin{array}{c}\text { er } \\
\text { s }\end{array}$ & $n$ & $w_{n 1}(t)$ & $w_{n 2}(t)$ & $\cdots$ & 0 & $p_{n 1}(t)$ & $p_{n 2}(t)$ & $p_{n m}(t)$ & & $w x_{n}(t)$ \\
\hline c & 1 & $q_{11}(t)$ & $q_{12}(t)$ & $\cdots$ & $q_{1 n}(t)$ & 0 & & & $\delta_{1}(t)$ & $r x_{1}(t)$ \\
\hline $\begin{array}{c}\mathrm{ns} \\
\mathrm{u}\end{array}$ & 2 & $q_{21}(t)$ & $q_{22}(t)$ & $\cdots$ & $q_{2 n}(t)$ & & & & $s_{2}(t)$ & $r x_{2}(t)$ \\
\hline$m$ & $\vdots$ & $\vdots$ & & & & & & & $\vdots$ & \\
\hline $\mathrm{s}$ & $m$ & $q_{m 1}(t)$ & $q_{m 2}(t)$ & $\cdots$ & $q_{m n}(t)$ & & & 0 & $s_{m}(t)$ & $r x_{m}(t)$ \\
\hline & & $f_{1}(t)$ & $f_{2}(t)$ & & & & & & & \\
\hline
\end{tabular}

In Table 2, the values in the hoczontal bar stand for the label number of inflow nodes, the values in longitudinal barstand for outflow nodes. The values in the table are outflows of various kinds of nodes, and the whole table is accumulated in the horizontal.

As can be seen from the table, up tor the point, the cumulative outflows of various kinds of nodes are as follows:
(1) manufacture:
$\sum_{i=1}^{n} f_{i}(t)$

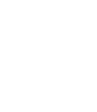

(2) wholesaler $i$ :

$$
w x_{i}(t)=\sum_{\substack{j=1 \\ i \neq 1}}^{n} w_{i j}(t)+\sum_{j=1}^{m} p_{i j}(t)+g_{i}(t), i=1,2, \cdots, n
$$

(3) retailer $t$

$$
\text { (4) } x_{i}(t)=\sum_{j=1}^{n} q_{i j}(t)+\sum_{\substack{j=1 \\ i \neq j}}^{m} r_{i j}(t)+s_{i}(t), i=1,2, \cdots, m
$$

(2)Total Inflows of the Nodes in the system

In the Drug Logistics System, the total inflows of the nodes are as shown in Table3.

\begin{tabular}{|c|c|c|c|c|c|c|c|}
\hline \multirow{2}{*}{$\begin{array}{r}\text { Inflow } \\
\text { nodes } \\
\text { lnflow } \\
\text { Nodes }\end{array}$} & \multicolumn{3}{|c|}{ wholesalers } & \multicolumn{3}{|c|}{ retailers } & \multirow{2}{*}{$\begin{array}{l}\text { manufactu } \\
\text { res }\end{array}$} \\
\hline & 1 & 2 & $n$ & 1 & 2 & $m$ & \\
\hline
\end{tabular}

Table 3 Total Inflows of the Nodes in the Drug Logistics System 


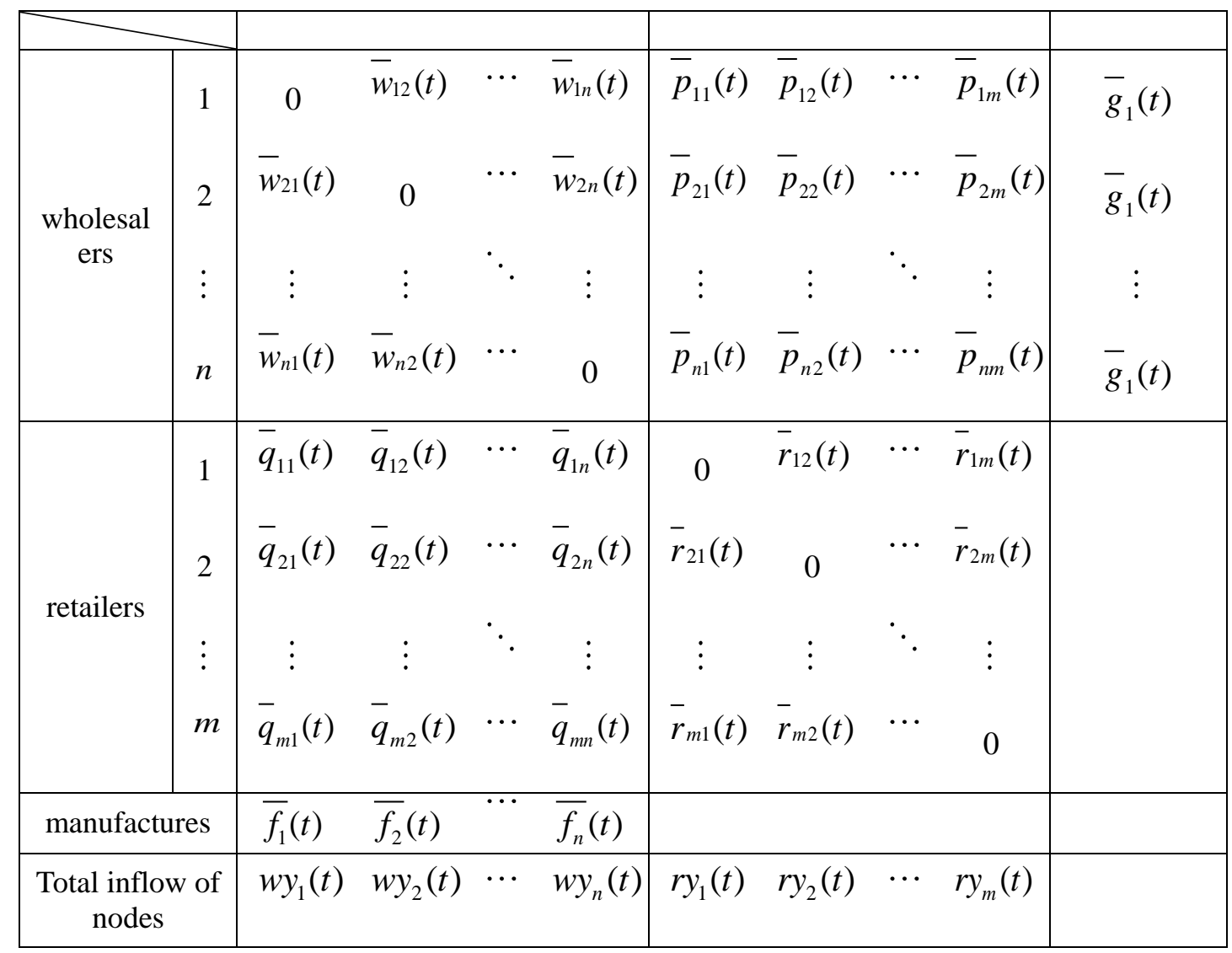

As can be seen from the table, up to t time point, the cumulative inflows of various kinds of nodes are as follows:

(1) manufacture:

$\sum_{i=1}^{n} \bar{g}_{i}(t)$

(2) wholesaler $j$ :

$w y_{j}(t)=\sum_{\substack{i=1 \\ i \neq j}}^{n} \bar{w}_{i j}(t)+\sum_{j=1}^{m} q_{i j}(t)+\bar{f}_{j}(t), j=1,2, \cdots, n$

(3) retailet $j$ :

$r y_{j}(t)=\sum_{i=1}^{n} p_{i j}(t)+\sum_{\substack{i=1 \\ i \neq j}}^{m} \bar{r}_{i j}(t), j=1,2, \cdots, m$

(3)Inventories of the Nodes in the system

At the t time point, the inventory of each node =total inflows - total outflows. So the inventory of the wholesaler is:

$w z_{i}(t)=w y_{i}(t)-w x_{i}(t), \quad i=1,2 ; \cdots n$

The inventory of the retailer is :

$r z_{i}(t)=r y_{i}(t)-r x_{i}(t) \quad i=1,2 ; \cdot m$

\subsection{Real-time Monitoring Network Traffic Model}

On the basis of the dynamic changeable flow model and the cumulative static flow model, we further establish Real-time Monitoring Network Traffic Model of drug logistics system. 
According to the mechanism of Drug Logistics System Network traffic monitoring and symbols in this chapter, the process can be converted as shown in Figure 4.

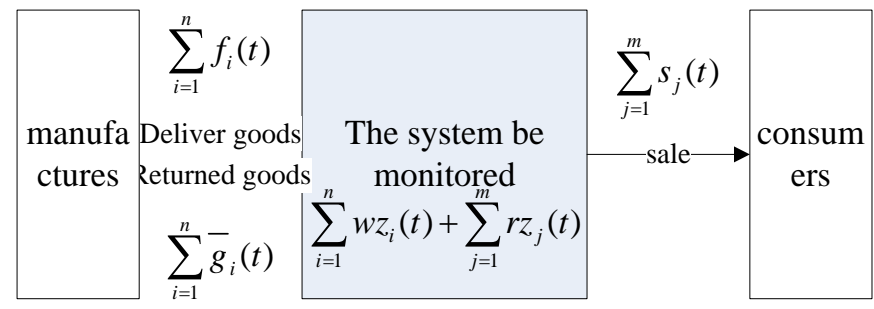

Figure 4 the Flows Monitoring Model

According to Figure 4, the total flow monitoring coefficient of the Drug Logistics System can be expressed as:

$\delta(t)=\sum_{i=1}^{n} f_{i}(t)-\left[\sum_{i=1}^{n} \bar{g}_{i}(t)+\sum_{j=1}^{m} s_{j}(t)\right]-\left[\sum_{i=1}^{n} w z_{i}(t)+\sum_{j=0}^{m} r z(t)\right]$

Through observing the changes of $\delta(t), w z_{i}(r)(t)(i=1,2, \cdots, n, j=1,2, \cdots, m)$, with the system state time, we can realize thereal-time and automatic monitoring of the Drug Logistics System. That is to say:

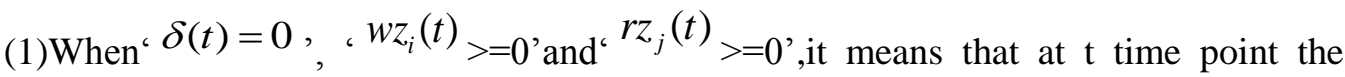
network traffic is normal, no illegal drugs beingmixed in.

(2)When' $\delta(t)=0$, , but $w z_{\gamma}(t)$ or $z_{j}(t)$ or both of them are negative, it means that at time point the network traffic is abnormal, iffegal drugs being mixed in.

(3)When ' $\delta(t)<0$, it means that at trme point the network traffic is abnormal, illegal drugs being mixed in.

\section{The validation of the Drug Logistics System Network Flows Monitoring model}

This paper will follow the general steps of system modeling and simulation, establishing the simulation model designing the simulation program, setting simulation parameters and analyzing the simulation results. Consequently, we can validate the feasibility of the Drug Logistics System Network Flows Monitoring model in practical application.

\subsection{The Baekground of the Simulation Model}

The network structure of the system simulation model of this paper is established as shown in Figure 5.

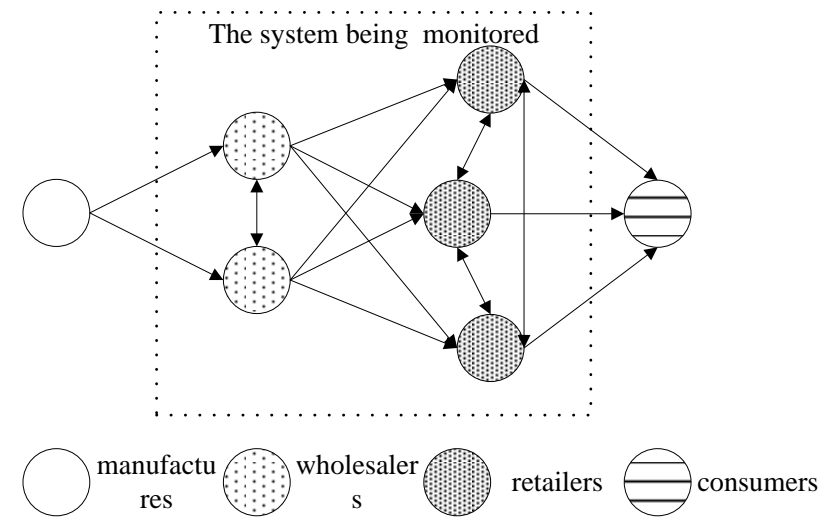




\section{Figure 5 Network Structure of the Drug Logistics System for the System Simulation Model}

This Drug Logistics System Network is composed of one producer, two wholesalers, three retailers and a plurality of consumers (all consumers are abstracted into one node in Figure 5.Drug logistics activities exist between manufacturers and wholesalers, wholesalers and wholesalers, retailers and retailers, wholesalers and retailers, which are mostly forward logistics.

\subsection{The Establishment of Simulation Model}

On the basis of the network structure of drug logistics system simulation model, in this section we will use the AnyLogic software to establish the system simulation model, realizing the simulation of the drug logistics system operation process[20]. The established simulation model is as shown in Figure 6.

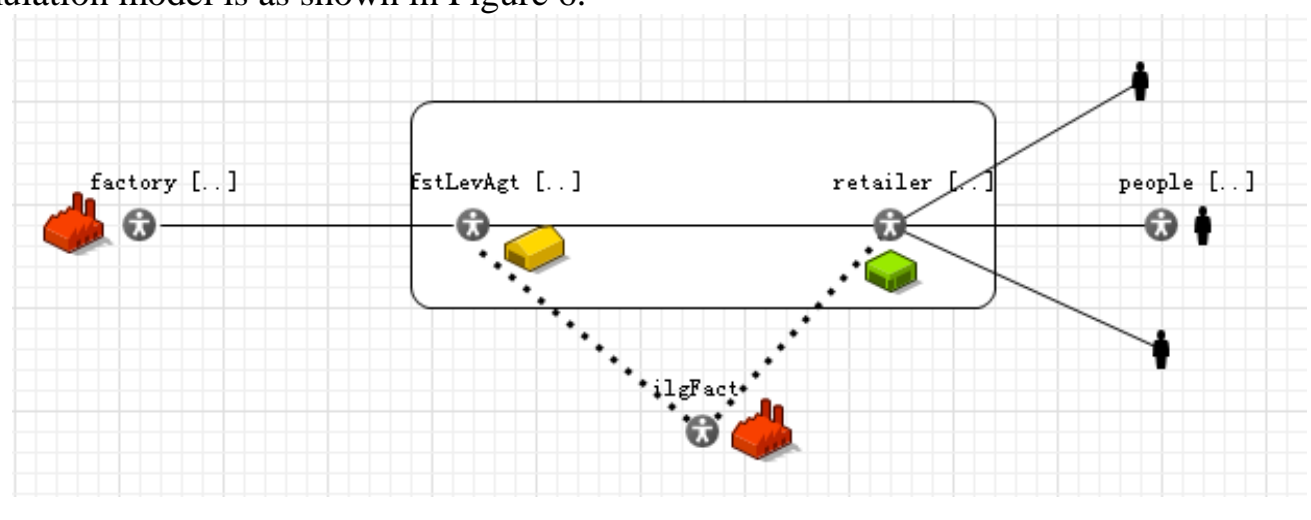

Figure 6. The Main Model of Any Logic Software Simulation

In the simulation model, there is one manufacturer Agent, two wholesalers Agent, three retailers Agent and one hundred consumers Agent. To simulate the illegal drug being mixed in the drug logistios system, we set up one illegal manufacturer Agent in this model, which has the logistics connections between manufacturers Agent and retailers Agent.

\subsection{The Analysis of Sinnulation Results}

Setting the states of various Agents, operating parameters of Figure 6, running the AnyLogic simulation program and dealing with the simulation data. The results are as shown in Figutre 7 and Figure 8. 


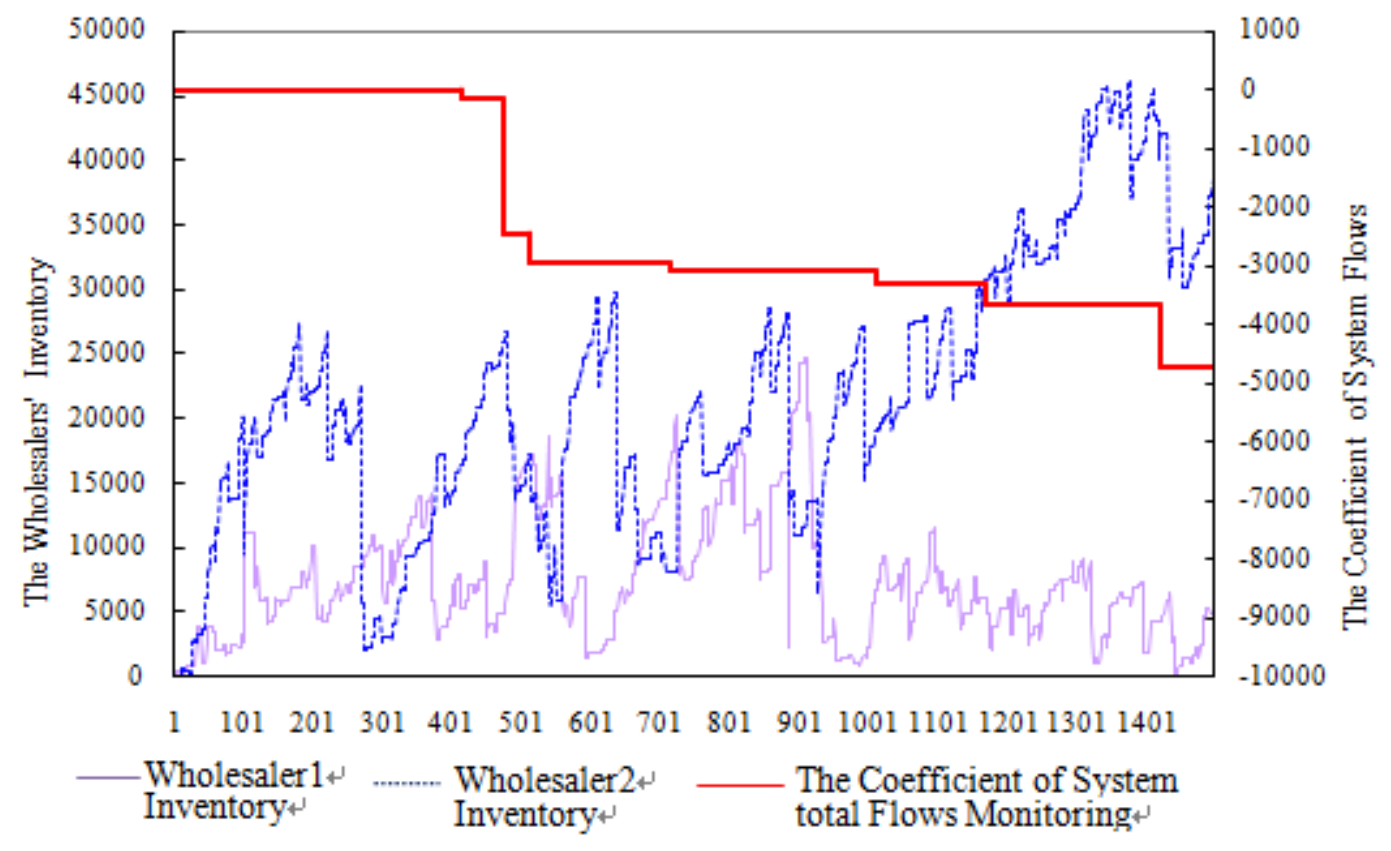

Figure 7. The Wholesalers' Inventory and the Coefficient of System Flows Monitoring during the Simulation of Drug Logistics System

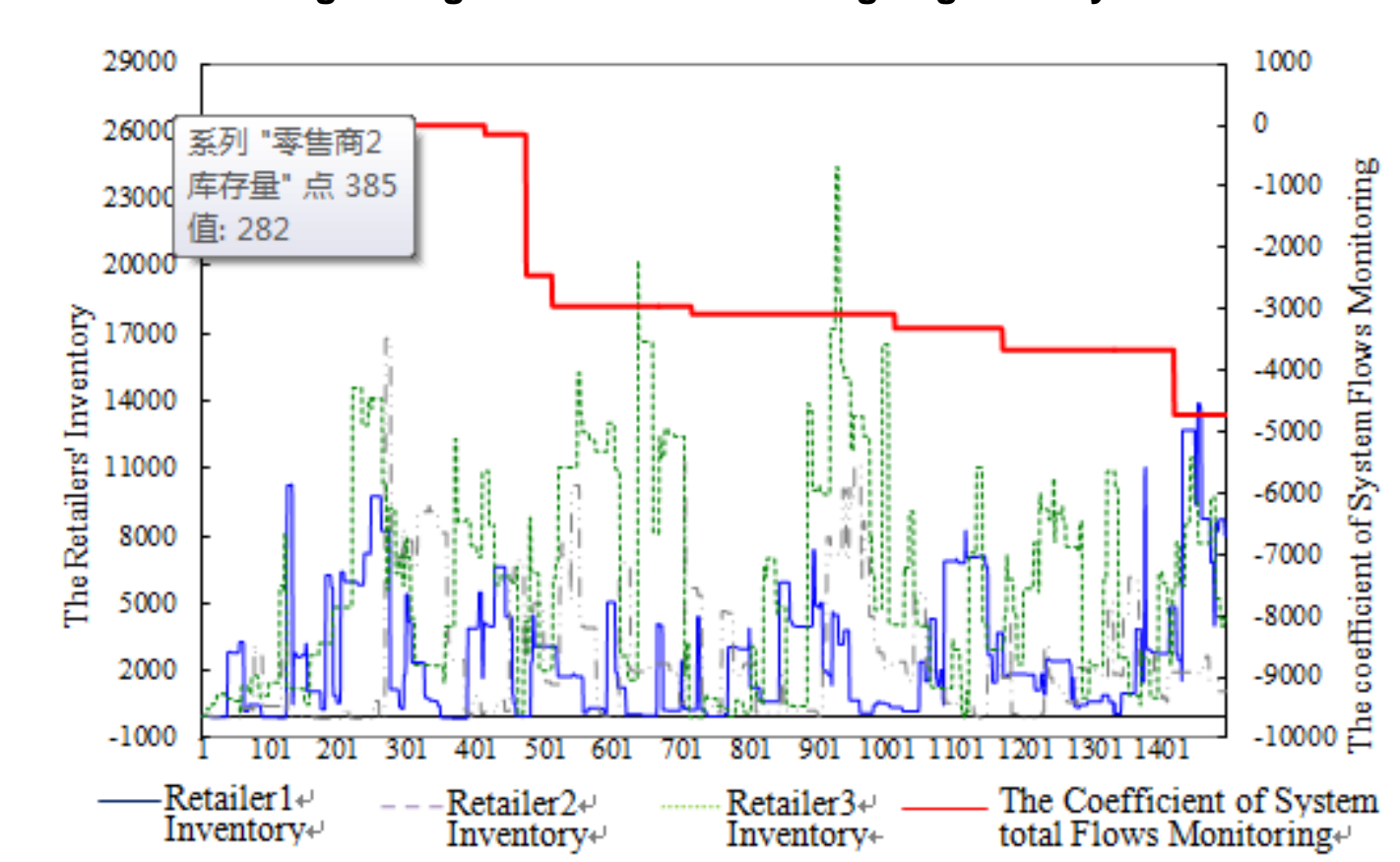

\section{Figure 8. The Retailers' Inventory and the Coefficient of System Flows Monitoring during the Simulation of Drug Logistics System}

As shown in Figure 7:

(1)During the operation of drug logistics system simulation, although there are different level waves of the inventories of the two wholesalers, the inventory of each point is positive. It shows that wholesalers operate normally, not appearing the manufacturing of illegal drugs.

(2)The total flow monitoring coefficient turns from zero to a negative value and once is dropped like the ladder, suggesting that there are illegal drugs mixing in the system more than once. 
As shown in Figure 8:

(1)During the operation of drug logistics system simulation, three retailers' inventories are expressing different level waves and there are negatives in some time points. It shows that retailers operate abnormally, existing the selling of illegal drugs.

(2)Similar to the Figure 7, the total flow monitoring coefficient turns from zero to a negative value and once is dropped like the ladder, suggesting that there are illegal drugs mixing in the system more than once.

From the simulation results of the Figure 7 and Figure 8, we can see that the Real-time Flows Monitoring Network Traffic Model of Drug Logistics System can realize the real-time and automatic monitoring of the entire system's drug circulation status, that is to say, the model is feasible in practical application.

\section{Conclusion}

Based on the actual situation in China, the network flows regulation mechanis m of drug logistics system is proposed and a network flows real-time mónitoring prodel is established in this paper. Then the dissertation does the simulation and simulates using the AnyLogic software on the model and the simulation results shov that the model can automatically monitor the drug circulation of the entire system in real-time. These researches can provide a new kind of advanced controlling drug regulation method, which has the characteristics of being dynamic, real-time and effective, for relevant departments.

The model established in this paper assumes that the drug transportations among nodes in the system are instantaneous, without eonsidering the time consumed by the drug transportation. Therefore, the follow-rip studies san be perfect on the basis of taking drug transport time into consideration. (In) addition, though the model can detect abnormal situations, it cannot achieve the function of the abnormal points tracking of network flows, which deserves further researches.

\section{Acknowledgement}

This paper is based on Beijing Social Science Fund "Research on Family Pharmaceutical Reverse Logisties in Beijing" (14JDJGB035), and Laboratory of Logistics and Technology.

\section{References}

[1] The Ministry of Commerce,the State Food and drug administration. The notice on strengthening management of drug circulation industry (Ministry of Commerce [2009]571) [EB/OL].2009, 11. http://yww sda.gov.cn/ WS01/ CL0056/ 44355.html.

[2] The State Food and drug administration. Notice of varieties basic drugs electronic supervision (the State Food and Drug Administration Office[2010]194).2010, 5. http://www.sda.gov.cn/ WS01/ CL0055/ 49153.html.

[3] EengShouQing.Drug safety and digital supervision.JiNan:Shandong University, 2009: 4-10.

[4] Ruan xiufang. The Research on Inergration of Sytem Building in Sate Administration [D].Shanghai:Shanghai jiaotong university, 2008: 9-21.

[5] Crowe,Ann H.Electronic Supervision: From Decision-Making to Implementation.Corrections Today. Aug2002, Vol. 64 Issue 5, p130. 3p.

[6] DeMichele, Matthew\&Payne, Brian. Electronic Supervision and the Importance of Evidence-Based Practices. Federal Probation. Sep2010, Vol. 74 Issue 2, p4-11. 8p

[7] DING Jin-xi, LI Yuan, GAO Qiang. Research on Drug Electronic Supervision Policy under the Framework of National Essential Drug System. China Pharmacy.2011

[8] Ma Xiaoyu, Mo Yingning. Reflections on China's Implementation of Electronic Monitoring of Drugs. Chinese Pharmaceutical Affairs. 2014, (9).

[9] Bi Wenya. Discussion on Problems in Electronic Supervision of Essential Drugs and Counter measures. Chinese Pharmaceutical Affairs. 2014, 28(1).

[10] HongGang.Study on the Development Progress of Drug Logistics in China. Chinese Pharmaceutical Affairs.2009.

[11] GUOShao-lai,LIUGui-yang,GUODai-hong,LIUDong-jie,CAIJing-chuan,FUXiao-qun.Study and realiza 
tion of drug supply logistics guarantee system.Chinese journal of drug application and monitoring.2008.

[12] He Xuejun, Zheng Ping, Guo Hongwei, Li Lei. Analysis of Development Tendency of Logistics of Pharmaceutical Industry in China. Value Engineering. 2012, 31(4)

[13] Xia Xudong, Li Hanjian, Song Lili. The Problems and Development Countermeasure of Chinese Medical 3PL. Chinese Pharmaceutical Affairs. 2009(2)

[14] Hong Sik Kim, So Young Sohn. Cost of ownership model for the RFID logistics system applicable to u-city[J]. European Journal of Operational Research, 2009, 194: 406-417.

[15] HeMingKe.Logistics System Study.Beijing:Higher Education Press.2004:213.

[16] Tu xuyan, Wang cong,Guo yanhui. Macro System Cybernetics [M].Beijing:Beijing University of Posts and Telecommunications Press, 2005: 93-94.

[17] Zhang Wenjie, Zhang Keming. Logistics System Analysis[M].Beijing: Higher Education Press, 2008: 1.

[18] Yang guanghua,Li xiamiao,Xie xiaoliang. Represent Model and Structural Analysis of Regional Logistics Network[J].Application Research of Computers, 2009, 26(10): 3743-3745. 4-10.

[19] Yu, Hong .Electronic Pills for Medication Compliance Monitoring[J].ProQuest,UMI Dissertations Publishing, 2010. 3467780.

[20] Li,Bingdong.Network Security Monitoring and Analysis based on Big Data Technologies[J].Pro, Quest, UMI Dissertations Publishing, 2013. 3608749. 